\title{
AMNIOTIC MEMBRANE TRANSPLANTATION - ANALYSIS OF STRUCTURAL CHARACTERISTICS IN AMNIOTIC MEMBRANE TRANSPLANT AND CORNEAL ULCERS
}

\author{
Yana Manolova ${ }^{1}$, Zarka Stoycheva $^{1}$, Yordan Yordanov ${ }^{2}$, Christina Grupcheva $^{1}$ \\ ${ }^{1}$ Department of Ophthalmology and Visual Sciences, Faculty of Medicine, \\ Medical University of Varna \\ ${ }^{2}$ Specialized Eye Hospital - Varna
}

\begin{abstract}
AIM: To analyze the structural characteristics in the cornea and the amniotic membrane (AM) with the help of laser scanning in-vivo confocal microscopy (IVCM) and to evaluate the morphometric changes in the cornea and the integration pattern of amniotic membrane into the host tissue using anterior-segment optical coherence tomography (AS-OCT) in patients with persistent corneal defects treated with amniotic membrane transplantation (AMT).
\end{abstract}

MATERIALS AND METHODS: Nine eyes of six consecutive patients (mean age $44.9 \pm 8.7$ years) with corneal defects and stromal thinning unresponsive to topical treatment were enrolled in this study. Transplantation of cryopreserved amniotic membrane was performed. The time of healing of the corneal defect, morphometric analysis of the cornea and transplanted amniotic membrane using AS-OCT and the structural characteristics in the amniotic membrane grafts, and corneal ulcers assessed by in vivo confocal microscopy were evaluated.

RESULTS: Successful results after amniotic membrane transplantation (AMT) were observed in 8 of the 9 eyes $(91.2 \%)$. On the $2^{\text {nd }}$ day after transplantation, IVCM showed that under the amniotic membrane a new epithelium with large, flat, immature cells of the superficial corneal epithelium with an average density of $598.4 \pm 66.38 \mathrm{cells} / \mathrm{mm}^{2}$ was observed. The basal cells also showed immaturity and their average density was $1804 \pm 93.32 \mathrm{cells} / \mathrm{mm}^{2}$. In the corneal stroma edema and activated corneal cells were visualized. The average corneal epithelium thickness increased to $24.60 \pm 2.07 \mu \mathrm{m}$, the average density of epithelial cells increased to $657.6 \pm 78.41 \mathrm{cells} / \mathrm{mm}^{2}$, while the mean basal epithelium cell density was $2541 \pm 540.13 \mathrm{cells} / \mathrm{mm}^{2}$. AS-OCT showed that the preoperative corneal thickness at the ulcer was $418.91 \pm 96.56 \mu \mathrm{m}$. On the $2^{\text {nd }}$ day after the surgery, the amniotic membrane (AM) thickness was measured to be $268 \pm 105 \mu \mathrm{m}$. On the $8^{\text {th }}$ day it was two times smaller and was measured to be $123 \pm 39 \mu \mathrm{m}$. On the $25^{\text {th }}$ day post-surgery the corneal thickness was measured at $494.03 \pm 67.35 \mu \mathrm{m}$. In two of the cases integration of $A M$ was found.

CONCLUSIONS: AMT leads to recovery of corneal defects unresponsive to conservative treatment. The amniotic membrane graft is effective in promoting re-epithelialization, nonetheless, it can also integrate into the host corneal tissue, which results in an increase in corneal thickness, stabilization of the epitheli$u m$, and reduction of the subjective signs. The in-

Address for correspondence:

Yana Manolova

Specialized Eye Hospital

15 Doyran St.

Varna

e-mail:y.m.manolova@gmail.com

Received: February 27, 2017

Accepted: March 31, 2017 tegration of amniotic membrane into the damaged cornea proves that AMT is an effective and irreplaceable procedure for difficult-to-treat anterior ocular surface diseases.

Keywords: amniotic membrane, corneal ulcer, ASOCT, IVCM, integration 
Yana Manolova, Zarka Stoycheva, Yordan Yordanov et al.

\section{INTRODUCTION}

The cornea is the outermost fibrous layer of the eye. It is a highly organized tissue that has no blood vessels and receives nourishment from tears and aqueous humor. Therefore, it is smooth, transparent and thus admits light into the eye. The cornea is the most essential structure of the ocular surface. The proper function of the cornea is important to the vision and the quality of life of the patients. Respectively, nature has developed several protective mechanisms such as bony orbits, eyelids, tear film, strong corneal, conjunctival epithelium and a submucosal secretory immunoglobulin system (29). Nonetheless, these mechanisms may be insufficient in cases, such as trauma, chemical burns, inflammations and diseases of the ocular surface. Despite the targeted proper medical treatment, in some cases, progression, such as vascularization, cicatrization and even loss of visual function is observed. Therefore, after the discovery of the benefits of the amniotic membrane, its transplantation to unresponsive to conservative treatment ocular surface diseases, became a gold standard.

The amniotic membrane (AM) is the innermost layer of the fetal membrane. It consists of three different layers: a stromal layer, a basement membrane, which is one of the thickest in the human body and a monolayer of cuboid epithelial cells $(1,2)$. The stroma can be divided into an acellular compact layer (lamina densa), a fibroblast layer (lamina fibroreticularis), and a spongy layer (lamina propria) (3). The main protein components of AM are collagen (type III, IV, V and VII), and proteoglycan (perlecan, bikunin, decorin), glycosaminoglycans, laminin, and fibronectin. It produces signaling molecules, such as epidermal growth factor (EGF), transforming growth factor beta (TGF- $\beta$ ), fibroblast growth factor (FGF) and platelet-derived growth factor (PDGF), which support its trophic function. AM contains no HLA - A, B, C antigens and $\beta 2$-microglobulin and hence immunological rejection after its transplantation does not occur (4). The aforementioned effects provide the anti-inflammatory (5), antifibroblastic (6), antibacterial (7) and antiangiogenic (8) properties of the AM. Thus, AM is an excellent substrate for growth, migration and adhesion of epithelial corneal and conjunctival cells and in the last decades it has been used as a gold standard for the treatment of a variety of ocular surface diseases, such as persistent epithelial defects, corneal ulcers, descemetocele, corneal perforation, limbal stem cell deficiency, symptomatic bullous keratopathy, band keratopathy, chemical injury, thermal injury, scleral perforation, etc. At the same time, AM has proven to be the best carrier substrate for ex vivo expansion of limbal stem cells (9) and corneal cells (10).

There is a variety of surgical techniques for amniotic membrane transplantation (AMT) depending on the desired outcome and ocular surface conditions. It can be used as a temporary graft (patch with epithelial side in contact with the corneal surface) to cover the exposed surface, influence epithelium healing, reduce inflammation and scarring and thus reduce pain (11). However, AMT can be performed as a permanent graft (epithelial side up) for corneal and/or conjunctival surface reconstruction. In this case it acts as a scaffold for corneal cells that may migrate on the amniotic membrane (12). If there is a deep corneal ulcer or perforation, the preferred surgical technique is an application of small pieces of AM with the proper size in order to fill in the corneal defect. Afterwards it is covered by an overlying larger piece, which acts as a bandage (13). When reepithelialization on the anteriormost layer of AM occurs, the rest of the AM pieces may incorporate into the cornea. This leads to thickening and stabilization of the corneal defect (14). It has been proven histologically that AM may integrate into the host tissue (15). Thus, the aim of our study was to analyze the changes, which occur in the amniotic membrane transplant and corneal defects in patients with the help of slit-lamp biomicroscopy, IVCM and AS-OCT.

\section{MATERIALS AND METHODS}

\section{Patients}

Six patients (9 eyes), including five males and one female, were enrolled in this study. The average age of the patients was $44.9 \pm 8.7$ years. They were referred to the Specialized Eye Hospital from other eye clinics on the territory of Northeastern Bulgaria because of persistent epithelial defects unresponsive to continuous medical treatment for at least 3 weeks and subjective signs such as pain, photophobia, tearing and objective signs like low vision, injection, and depth of the corneal defect. The medical treatment included antibiotic drops, preservative-free artificial 
eye drops, lubricants and therapeutic bandage contact lenses. All the patients had noninfectious corneal ulcers and stromal thinning. Two of the patients reported continuous use of topical proparacaine hydrochloride ophthalmic solution (Alcaine $0.5 \%$ ) in order to relieve the pain and discomfort. One of the patients was with exposure keratitis secondary to Bell's palsy and the rest of the patients had persistent epithelial defect due to trauma. The patients did not show clinical signs of limbal stem cell deficiency.

\section{Preoperative Examination}

In accordance with the Good Clinical Practice in Ophthalmology, the pre-operative examination of the patients included gathering and evaluating information about the clinical history of the patient and assessment of subjective signs.

For the observation of the anterior ocular surface and anterior ocular segment we used Reichert XCEL 400 slit lamp.

Amniotic Membrane Transplantation - Surgical Techniques

The Center for Translational Medicine and Cellular Therapy at the St. Marina University Hospital (Varna, Bulgaria) provided cryopreserved amniotic membranes. All AMs were prepared and preserved under all requirements for safety. The AMs tested negative for hepatitis $\mathrm{B}$ and $\mathrm{C}$ viruses, and syphilis.

All operations were performed by one surgeon using local anesthesia. The AM was pre-warmed at room temperature. The patient's loose epithelium was removed and Bauman's membrane was polished. In the cases with stromal thinning and corneal ulcer, the necrotic debris from the base and walls of the ulcer was removed. The AM was washed in order to remove the glycerine. AM was used to cover the cornea as a patch with the epithelial side down and was fixated to the episclera with 8-0 Vicryl suture in patients with surface defect (corneal defects that take up to $20 \%$ from the overall corneal thickness). In patients with in deep defects (a defect larger than 20\% from the overall corneal thickness) a combined procedure was used. AM pieces (2-5) were customized to fit and fill the corneal ulcer with stromal side down (towards the corneal defect) as a graft. A larger piece of AM was placed to cover entirely the cornea and limbus and was sutured to the episclera with 8-0 Vicryl. Afterwards, on top of the membrane, a therapeu- tic contact lens was applied. If needed, multiple amniotic membrane transplantations were performed.

Postoperative Treatment and Follow-Up

\section{Examination}

After the surgery, all patients received topical therapy with steroid, nonsteroidal drops and antibiotic drops and preservative-free lubricants. After the AM was removed, the therapy was changed in accordance with the current ophthalmic status of the patient. After that, healing preservative-free lubricants were kept as part of the regimen of the patient.

The follow-up examination was done by the use of slit-lamp biomicroscopy, AS-OCT and IVCM. A successful treatment would show stabilization of the corneal thickness and corneal epithelialization, pain relief and reduction of the levels of hyperemia. Unsuccessful treatment was considered to be a lack of corneal healing and persistence of subjective symptoms, such as pain, photophobia, hyperemia and tearing.

\section{In Vivo Confocal Microscopy}

The AM, the corneal defect pre-surgery and the entire area post-surgery on the $1^{\text {st }}$ and $8^{\text {th }}$ day were examined with Heidelberg Retina Tomograph II Rostock Cornea Module (HRT II-RCM). The instrument is equipped with water immersion objective lens with a magnification $63 \mathrm{x}$ - Zeiss as a light source $670 \mathrm{~nm}$ diode laser class 1 . The lens of the microscope is covered with a disposable, sterile cup PMMA (Tomocap) filled with lubricant (Corneregel) to achieve immersion. All examinations were performed under a topical anesthetic (Alcaine, 0.5\%) and through a therapeutic contact lens on the cornea.

\section{Anterior Segment Optical Coherence Tomography}

AS-OCT (Topcon, Hasunuma-cho, Itabashi$\mathrm{ku}$, Tokyo, Japan) with lateral resolution of $\leq 20 \mu \mathrm{m}$ and in-depth resolution of 5-6 $\mu \mathrm{m}$ was performed to assess the morphometric measurements at the site of the corneal defect both before and after surgery on the $1^{\text {st }}, 8^{\text {th }}$ and $25^{\text {th }}$ day.

\section{Statistical Analysis}

We used ANOVA on BANKS test for repeated measurements in order to assess differences of the parameters over time. The Student-Newman-Keuls method was applied and a p-value below $0.05 \%$ was considered statistically significant. 
Yana Manolova, Zarka Stoycheva, Yordan Yordanov et al.

\section{RESULTS}

\section{Slit-Lamp Examination}

The surgical success was obtained in all 8 out of 9 eyes. In the unsuccessful case, we had to perform multiple amniotic membrane transplantations, however, the case was excluded from the study. In 2 of the cases, integration of AM was found.

\section{In Vivo Confocal Microscopy}

IVCM of cryopreserved AM was performed in order to analyze the structures before transplantation and thus detect more detailed characteristics in it on a microstructural level after transplantation. The AM was pre-warmed at room temperature. The confocal microscopic findings showed five layers: monolayer of polygonal, amniotic epithelial cells with dark borders and bright cytoplasm (Figure 1), a thick basal membrane, a dense, compact homogenous layer and stroma with three distinct layers - a compact layer, a fibroblast layer with hyperreflective fibroblast cells and a spongy layer. (Figure 2). The average thickness of the AM was measured: $227.4 \pm 41.3 \mu \mathrm{m}$ and the average density of amniotic epithelial cells: $3126 \pm 60$ cells $/ \mathrm{mm}^{2}$.

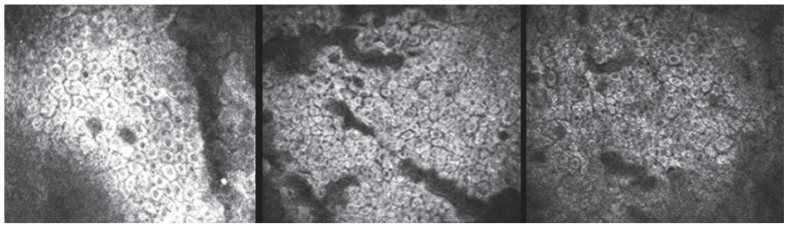

Figure 1. Representative in vivo confocal microscopy images of cryopreserved AM - polygonal, amniotic epithelial cells with dark borders and bright cytoplasm.

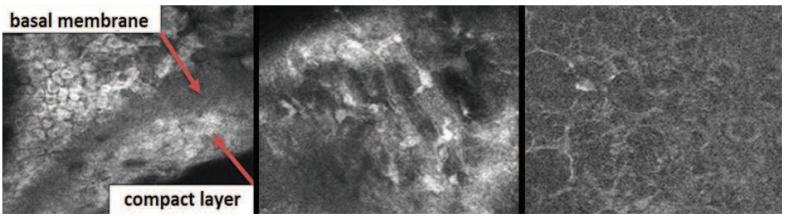

Figure 2. Representative in vivo confocal microscopy images of cryopreserved $A M$ - basal membrane and stroma - compact layer (left), fibroblast layer (middle) and spongy layer (right).

The microstructural characteristics in the AM were observed while obtaining IVCM images of the transplanted AM on the anterior ocular surface, where the corneal defect was located. Nevertheless, microstructural changes in the cornea were also assessed. On the $2^{\text {nd }}$ day of the transplantation the previously described layers of the AM patch were distinguishable. The average density of the amniotic epithelial cells was $3026 \pm 50$ cells $/ \mathrm{mm}^{2}$. The average thickness of the uppermost AM layer was $188 \pm 40 \mu \mathrm{m}$. Under the amniotic membrane a new epithelium with large, flat, immature cells of the superficial corneal epithelium with an average density of $598.4 \pm 66.38$ cells $/ \mathrm{mm}^{2}$ (Figure 3) was observed. The basal cells also showed immaturity and their average density was $1804 \pm 93.32$ cells $/ \mathrm{mm}^{2}$. In the corneal stroma, edema and activated corneal cells were visualized (Figure 4). Due to increased reflectivity, the organization of the multiple layers of AM filling the corneal defect was masked.

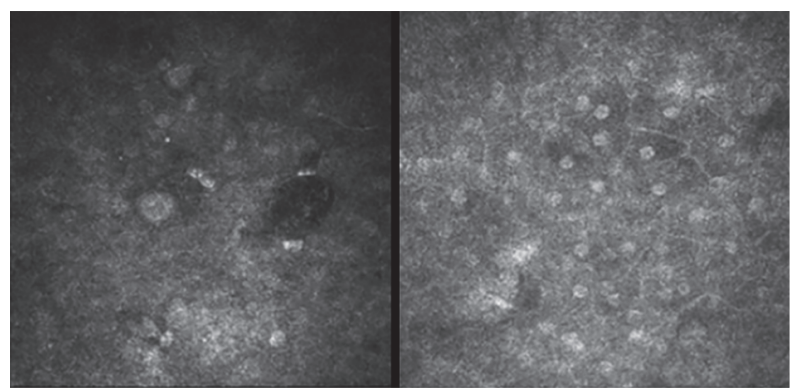

Figure 3. Representative superficial corneal epithelium cells - the average density of the superficial corneal epithelium cells (large, flat, immature) on the $2^{\text {nd }} d a y$ after the AMT was $598.4 \pm 66.38$ cells $/ \mathrm{mm}^{2}$

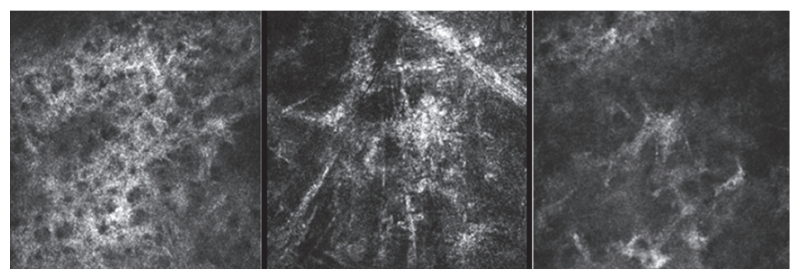

Figure 4. IVCM images of the corneal stroma underneath the AM on the $2^{\text {nd }}$ day after the surgery: activated corneal keratocytes and tissue edema in the anterior stroma (left), visible nerve fibers in the middle stroma (middle), reduced keratocytes activity within the posterior stromal layer (right).

On the $8^{\text {th }}$ day after the surgery, the AM showed progressive changes. The average amniotic epithelial cells density was $2196 \pm 64$ cells $/ \mathrm{mm}^{2}$. The epithelization of the corneal epithelium occurred under the external amniotic bandage, while it disintegrated. The average corneal epithelium thickness increased to 
$24.60 \pm 2.07 \mu \mathrm{m}$, the average density of epithelial cells increased to $657.6 \pm 78.41 \mathrm{cells} / \mathrm{mm}^{2}$, while the mean basal epithelium cells density was $2541 \pm 540.13$ cells/ $\mathrm{mm}^{2}$. Both epithelial layers gradually began to show visible signs of maturity (Figure 5).

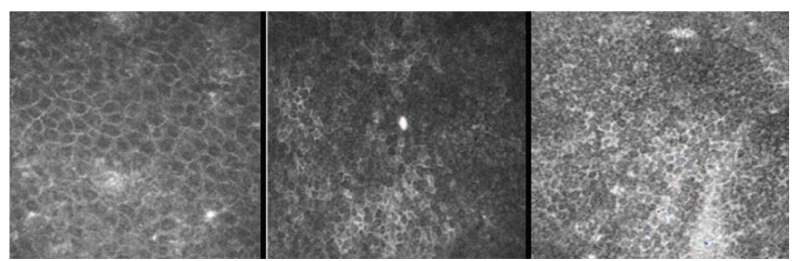

Figure 5. IVCM images from the $8^{\text {th }}$ day post-surgery: the superficial corneal epithelial cells with some visible signs of immaturity (left), basal epithelial cells of the cornea (middle and right).

On the $25^{\text {th }}$ day post-surgery, increase in the density of mature superficial and basal cells was observed, as well as occurrence of subbasal nerve plexus and normal distribution of keratocytes in the stroma (Figure 6).

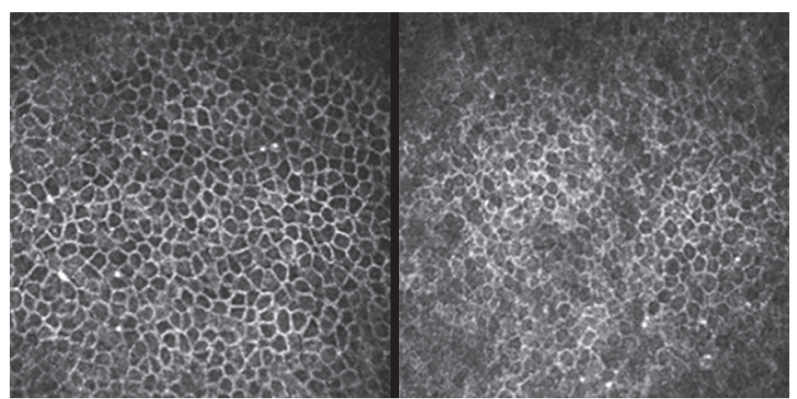

Figure 6. IVCM images of superficial and basal corneal cells 25 days after AMT.

\section{Anterior Segment Optical Coherence Tomography}

AS-OCT scans were performed before the surgery in order to assess the information about the morphometric parameters of the cornea and the size of the corneal defect (the thinnest point of the cor- nea). Consequently, on the $8^{\text {th }}$ and $25^{\text {th }}$ day post-surgery, the data was compared (Table 1).

The average thickness of the AM, measured on the $2^{\text {nd }}$ day after AMT, was $265 \pm 105 \mu \mathrm{m}$. (Figure 7). On the $8^{\text {th }}$ day, the thickness was reduced to $122 \pm 36 \mu \mathrm{m}$.
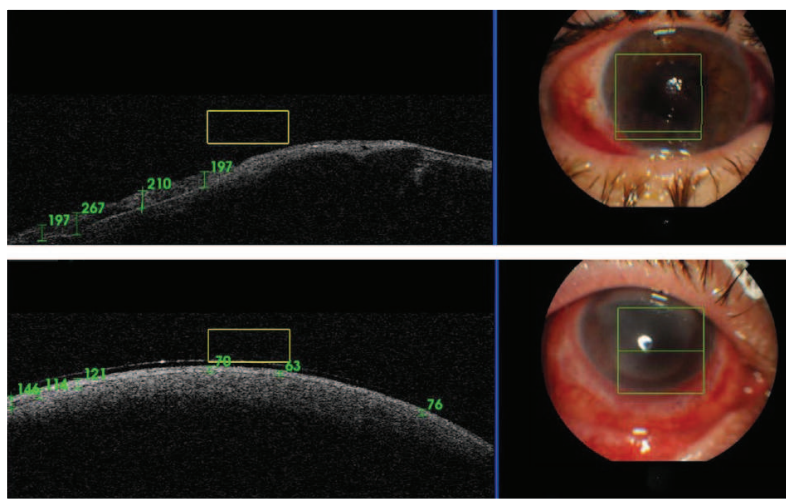

Figure 7. AS-OCT images. The AM thickness is measured on the $2^{\text {nd }}$ day after the surgery.

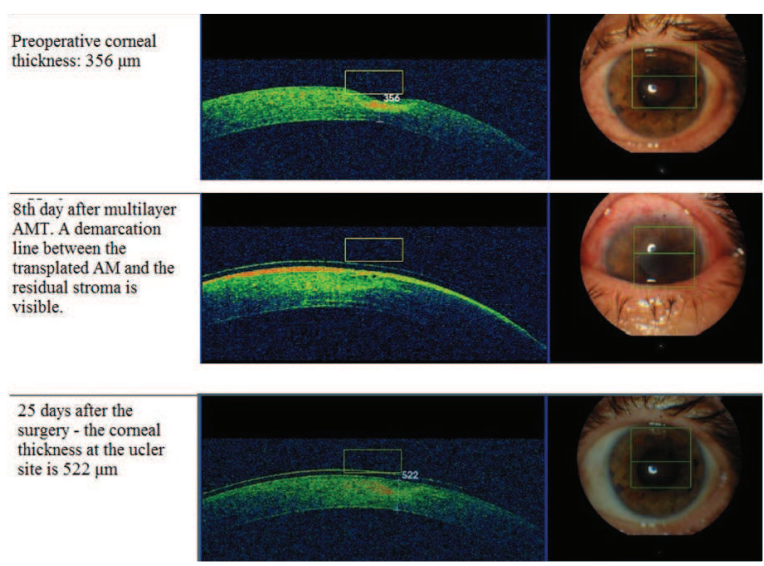

Figure 8. Representative case of a patient with pesistent epithelial defect (after foreign body removal). Preoperatively, the thinnest point of the ulcer bed measured 356 $\mu m$. On the $8^{\text {th }}$ day post surgery, the amniotic membrane layers were filling the ulcer bed, the overlying AM bandage as well as the therapeuc contact lens were clearly distinguishable. On the $25^{\text {th }}$ day, the corneal thickness at the ulcer site measured $522 \mu \mathrm{m}$.

Table 1. AS-OCT measurements before surgery, on the $8^{\text {th }}$ and $25^{\text {th }}$ day.

\begin{tabular}{l|c|c|c} 
& $\begin{array}{c}\text { Corneal thickness }(\mu \mathrm{m}) \\
\text { before surgery }\end{array}$ & $\begin{array}{c}\text { Corneal thickness }(\mu \mathrm{m}) \\
8^{\text {th }} \text { day post-surgery }\end{array}$ & $\begin{array}{c}\text { Corneal thickness }(\mu \mathrm{m}) \\
25^{\text {th }} \text { day post-surgery }\end{array}$ \\
\hline Persistent epithelial defects & $459.72 \pm 95.56$ & $516.17 \pm 62.68$ & $493.96 \pm 68.42$ \\
P values & 0.131 & 0.001 & 0.085 \\
\hline
\end{tabular}



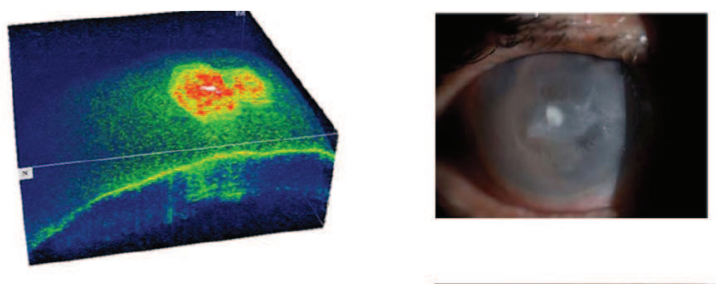

Second month after AMT
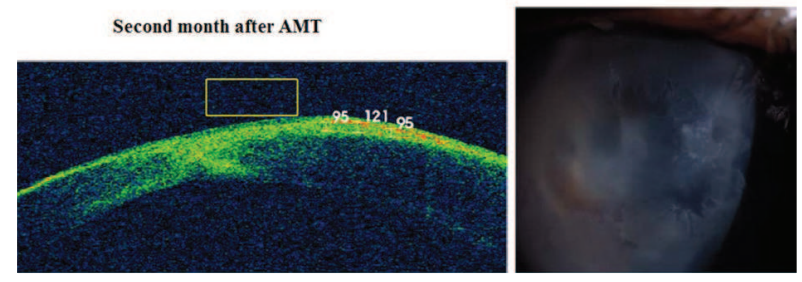

Figure 9. AS-OCT images 2 months after AMT (right) and slit-lamp photography (right). The AM integration into the stroma is clearly observed.

In two of the cases integration of AM into the host tissue was observed. During slit-lamp biomicroscopy intracorneal presence of the AM was detected. AS-OCT examination proves the existence of parts of the transplanted tissue into the cornea (Figure 9).

The integration of the amniotic membrane is associated with the formation of adhesion structures that provide stability of the regenerating corneal epithelium. This occurs when the epithelium grows between the Bowman membrane and the amniotic membrane.

\section{DISCUSSION}

Amniotic membrane transplantation has been used for the treatment of various unresponsive to topical medication ocular surface diseases during the last two decades $(16,17)$. It is clearly demonstrated that AMT has a positive effect on the healing process of the damaged eye and its application is indispensable for the reduction of prominent subjective symptoms like pain, photophobia, tearing and hyperemia (18). AMT has been used also during pterygium surgeries $(19,20)$. However, the most essential benefit of AMT is a stable increase in the corneal thickness and re-epithelialization. The overall success rate in the study was similar to the reported in previous clinical investigations $(16,21,12,14,22,23)$. In order to obtain more detailed information and better follow-up post-surgery investigation after AMT, not only slitlamp biomicroscopy should be performed, but also AS-OCT. It provides the opportunity for objective assessment of pre- and post-operative quantification of the corneal thickness and morphology.

In 2011, Nubile et al. (21) published results of a study examining the morphometric changes in the cornea in patients with deep corneal defects. Preoperatively, the measured thickness of the ulcer bed was $222 \pm 70 \mu \mathrm{m}$. Six months after the surgery the corneal thickness was stabilized and measured less compared to the data obtained on the first days after the transplantation. The authors describe that the demarcation line is most visible until the third month after the transplantation and the surrounded tissue is with high reflectivity. Our study using AS-OCT presents similar results in terms of a significant improvement in the corneal thickness measured on the $8^{\text {th }}$ day after the surgery. On the $25^{\text {th }}$ day, stabilization of the corneal thickness was observed as well as a decline of approximately $10 \%$ compared to the thickness assessed on the $8^{\text {th }}$ day.

Interestingly, Zakaria and associates published a study aiming to examine the value of AS-OCT intraoperatively during pannus resection and long-term postoperative follow-up of cultivated limbal epithelial stem cell transplantation (CLET) surgery. They proved that under intraoperative AS-OCT guidance the removal of the corneal pannus can be performed more precisely reducing the risk of extreme thinning iatrogenic ectasia and wound dehiscence while providing a smooth recipient surface for the composite graft (30). This suggests that the AS-OCT images are a valuable tool not only for pre- and post-surgical valuation, but also during surgery leading to better and more accurate results.

Several studies $(14,21,23,24)$ were conducted describing profoundly the recovery of stromal thickness using a multilayer AMT. In order to reach a better outcome after amniotic membrane transplantation, the surgical techniques, as well as the side of the $\mathrm{AM}$, should be well known. It has already been proven that the successful epithelialization and stabilization of the cornea depends on the position of the AM. Reepithelialization can occur on or under the outermost layer $(25,17,26,21)$. Amniotic membrane patch was placed with the epithelial side in contact with the corneal surface of the healing epithelium (11). When AMT is performed as a permanent graft with the epithelial side up, it acts as a scaffold for corneal cells 
that may migrate on the amniotic membrane (12). When multilayer technique is used, the reepithelialization occurs on the anteriormost layer of AM and the rest of the AM pieces may incorporate into the cornea. This leads to thickening and stabilization of the corneal defect (14). In 2006, Resch et al. $(15,26)$ first described histologically that the AM may integrate into the host tissue. According to them there are 3 different patterns of amniotic membrane integration: subepithelial integration of AM (corneal epithelium covering top of AM stroma); intraepithelial integration of AM (corneal epithelium sandwiching the AM stroma) and intrastromal integration of AM (corneal epithelium covering the AM stroma integrated into the corneal stroma).

The morphology of the various patterns of integration depends on the kind of anterior ocular disease and the surgical amniotic membrane transplantation technique. On slit-lamp biomicroscopy and according to the data obtained from the AS-OCT and IVCM, the patterns of amniotic membrane integration of our patients correspond to the intrastromal integration of AM described by Resch et al.

Most reported studies indicate integration after a multilayer AMT $(24,26)$, which corresponded to our findings. Nonetheless, not only multilayer AMT, but also amniotic membrane, used as a patch to help restoration of the corneal epithelium, may lead to integration into the host tissue. Further investigation on the successful integration of AM onto the host tissue should be conducted.

Leucoma and low visual acuity is present in all of the described cases of integrated AM, as well as improvement and stabilization of the corneal thickness $(21,24,26)$. The variation of the amniotic membrane transparency and further researches on it may be interesting due to the integration process (28).

There are only two studies describing the changes that occur in the anterior ocular surface and amniotic membrane after transplantation $(21,27)$ with the help of IVCM. They were conducted by $\mathrm{Nu}-$ bile et al. In 2008, they studied patients with epithelial defects. Series of examinations using IVCM were performed until complete reepithelialization. There was a change in the morphology of the AM and a recovery of the corneal thickness. On the $1^{\text {st }}$ day after AMT the average density of the epithelial cells was
4613 cells $/ \mathrm{mm}^{2}$, the average thickness of the epithelium was $35 \mu \mathrm{m}$ and the average thickness of the stro$\mathrm{ma}-116 \mu \mathrm{m}$. Loss of amniotic epithelial cells was observed 15 days post-surgery. A complete reepithelialization occurred between the $1^{\text {st }}$ and $4^{\text {th }}$ week. These findings correspond to our results and show that AM promotes adhesion, migration and differentiation of epithelial cells. In 2011, patients with deep corneal defects were examined. They underwent combined AMT: multilayer AM filler and a cover of a monolayer AM. The follow-up period was 12 months. Re-epithelialization over the AM filler was observed on the 15 th \pm 5 day post-surgery. The uppermost AM layer degraded, while the filler went through tissue modifications, such as early loss of amniotic epithelial cells, change in the fibrillar structure and migration of keratocytes in the amniotic stroma. In our study, IVCM of the amniotic membrane, before and after transplantation, and the microstructural assessment showed that over the time, the AM degrades gradually, while the newly formed epithelium cells are immature and with a larger cell area compared to the healthy corneal epithelium layer. The IVCM images showed derived cells with bright nuclei, which populate the AM.

\section{CONCLUSIONS}

AMT promotes recovery of stromal thinning of the cornea when the use of topical medications is insufficient. The amniotic membrane graft can integrate into the host corneal tissue with resulting stable corneal thickness, epithelium and reduction of the subjective signs. The integration is associated with reepithelialization of the amniotic membrane transplant. However, visual impairment is often detected since the AM is not transparent. The integration of amniotic membrane into the damaged cornea proves that AMT is an effective and unreplaceable procedure with a lasting outcome.

\section{REFERENCES}

1. van Herendael BJ, Oberti C, Brosens I. Microanatomy of the human amniotic membranes. A light microscopic, transmission, and scanning electron microscopic study. Am J Obstet Gynecol. 1978 Aug 15;131(8):872-80.

2. Gheorghe A, Pop M, Burcea M, Serban M. New clinical application of amniotic membrane trans- 
Yana Manolova, Zarka Stoycheva, Yordan Yordanov et al.

plant for ocular surface disease. J Med Life. 2016;9(2):177-9.

3. Akle CA, Adinolfi M, Welsh KI, Leibowitz S, McColl I. Immunogenicity of human amniotic epithelial cells after transplantation into volunteers. Lancet Lond Engl. 1981 Nov 7;2(8254):1003-5.

4. Silini AR, Cargnoni A, Magatti M, Pianta S, Parolini O. The Long Path of Human Placenta, and Its Derivatives, in Regenerative Medicine. Front Bioeng Biotechnol [Internet]. 2015 Oct 19 [cited 2017 Jan 30];3.

5. Park WC, Tseng SC. Modulation of acute inflammation and keratocyte death by suturing, blood, and amniotic membrane in PRK. Invest Ophthalmol Vis Sci. 2000 Sep;41(10):2906-14.

6. Li W, He H, Chen Y-T, Hayashida Y, Tseng SCG. Reversal of Myofibroblasts by Amniotic Membrane Stromal Extract. J Cell Physiol. 2008 Jun;215(3):657-647. Talmi YP, Sigler L, Inge E, Finkelstein Y, Zohar Y. Antibacterial properties of human amniotic membranes. Placenta. 1991 Jun;12(3):285-8.

7. Hao Y, Ma DH, Hwang DG, Kim WS, Zhang F. Identification of antiangiogenic and antiinflammatory proteins in human amniotic membrane. Cornea. 2000 May;19(3):348-52

8. Grueterich M, Espana EM, Tseng SCG. Ex vivo expansion of limbal epithelial stem cells: amniotic membrane serving as a stem cell niche. Surv Ophthalmol. 2003 Dec;48(6):631-46.

9. Kawakita T, Espana EM, He H, Smiddy R, Parel J-M, Liu C-Y, et al. Preservation and Expansion of the Primate Keratocyte Phenotype by Downregulating TGF- $\beta$ Signaling in a Low-Calcium, SerumFree Medium. Invest Ophthalmol Vis Sci. 2006 May;47(5):1918-27.

10. Burman S, Tejwani S, Vemuganti GK, Gopinathan U, Sangwan VS. Ophthalmic applications of preserved human amniotic membrane: a review of current indications. Cell Tissue Bank. 2004;5(3):161-75.

11. Lee SH, Tseng SC. Amniotic membrane transplantation for persistent epithelial defects with ulceration. Am J Ophthalmol. 1997 Mar;123(3):303-12

12. Shi W, Chen M, Xie L. Amniotic membrane transplantation combined with antiviral and steroid therapy for herpes necrotizing stromal keratitis. Ophthalmology. 2007 Aug;114(8):1476-81.
13. Prabhasawat P, Tesavibul N, Komolsuradej W. Single and multilayer amniotic membrane transplantation for persistent corneal epithelial defect with and without stromal thinning and perforation. $\mathrm{Br} \mathrm{J}$ Ophthalmol. 2001 Dec;85(12):1455-63.

14. Seitz B, Resch MD, Schlötzer-Schrehardt U, Hofmann-Rummelt C, Sauer R, Kruse FE. Histopathology and ultrastructure of human corneas after amniotic membrane transplantation. Arch Ophthalmol Chic Ill 1960. 2006 Oct;124(10):1487-90.

15. DUA H. Amniotic membrane transplantation. Br J Ophthalmol. 1999 Jun;83(6):748-52.

16. Malhotra C, Jain AK. Human amniotic membrane transplantation: Different modalities of its use in ophthalmology. World J Transplant. 2014 Jun 24;4(2):111-21.

17. Manolova Y, Popov C, Grupcheva C. Amniotic membrane transplantation- excellent biological scaffold for anterior ocular surface reconstruction. Scr Sci Medica. 2016 Oct 3;48(3):65-72.

18. Luanratanakorn $P$, Ratanapakorn $T$, Suwan-Apichon O, Chuck RS. Randomised controlled study of conjunctival autograft versus amniotic membrane graft in pterygium excision. Br J Ophthalmol. 2006 Dec;90(12):1476-80.

19. Stephenson, Michelle. Treatment Options with Amniotic Membrane. Review of Ophthalmology;Nov2015, Vol. 22 Issue 11, p68

20. Nubile M, Dua HS, Lanzini M, Ciancaglini M, Calienno R, Said DG, et al. In Vivo Analysis of Stromal Integration of Multilayer Amniotic Membrane Transplantation in Corneal Ulcers. Am J Ophthalmol. 2011 May 1;151(5):809-822.e1.

21. Letko E, Stechschulte SU, Kenyon KR, Sadeq N, Romero TR, Samson CM, et al. Amniotic membrane inlay and overlay grafting for corneal epithelial defects and stromal ulcers. Arch Ophthalmol Chic Ill 1960. 2001 May;119(5):659-63.

22. Solomon A, Meller D, Prabhasawat P, John T, Espana EM, Steuhl K-P, et al. Amniotic membrane grafts for nontraumatic corneal perforations, descemetoceles, and deep ulcers. Ophthalmology. 2002 Apr;109(4):694-703.

23. Kruse FE, Rohrschneider K, Völcker HE. Multilayer amniotic membrane transplantation for reconstruction of deep corneal ulcers. Ophthalmology. 1999 Aug;106(8):1504-1510; discussion 1511. 
24. Dua HS, Gomes JAP, King AJ, Maharajan VS. The amniotic membrane in ophthalmology. Surv Ophthalmol. 2004 Feb;49(1):51-77.

25. Resch MD, Schlötzer-Schrehardt U, HofmannRummelt C, Sauer R, Kruse FE, Beckmann MW, et al. Integration patterns of cryopreserved amniotic membranes into the human cornea. Ophthalmology. 2006 Nov;113(11):1927-35.

26. Nubile M, Dua HS, Lanzini TE, et al. Amniotic membrane transplantation for the management of corneal epithelial defects: an in vivo confocal microscopic study. Br J Ophthalmol 2008;92(1):54-60.

27. Connon CJ, Doutch J, Chen B, Hopkinson A, Mehta JS, Nakamura T, et al. The variation in transparency of amniotic membrane used in ocular surface regeneration. Br J Ophthalmol. 2010 Aug;94(8):1057-61.

28. Lemp MA, Blackman HJ. Ocular surface defense mechanisms. Ann Ophthalmol. 1981 Jan;13(1):61-3.

29. Zakaria N, Ní Dhubhghaill S, Taal M, Berneman Z, Koppen C, Tassignon M-J. Optical Coherence Tomography in Cultivated Limbal Epithelial Stem Cell Transplantation Surgery. Asia-Pac J Ophthalmol Phila Pa. 2015 Dec;4(6):339-45. 